Revista de Biología Marina y Oceanografía

Vol. 48, №3: 647-651, diciembre 2013

DOI 10.4067/S0718-19572013000300022

Nota Científica

\title{
Primer registro en Chile de diciémidos simbiontes en el pulpo pigmeo Robsonella fontaniana (Cephalopoda: Octopodidae)
}

First record in Chile of dicyemids in the pygmean octopus Robsonella fontaniana (Cephalopoda: Octopodidae)

\author{
Gabriela Muñoz', Sebastián Rodríguez ${ }^{1}$, Rosa Guerra² y Chita Guisado ${ }^{1}$ \\ ${ }^{1}$ Facultad de Ciencias del Mar y de Recursos Naturales, Universidad de Valparaíso, Avenida Borgoño 16344, Reñaca, Viña del \\ Mar, Chile.gabriela.munoz@cienciasdelmar.cl \\ ${ }^{2}$ Facultad de Ciencias, Universidad de Valparaíso, Gran Bretaña 1111, Playa Ancha, Valparaíso, Chile
}

\begin{abstract}
Dicyemids are commensals or parasites which live in the renal organs of benthic cephalopods. This study reports the presence of a dicyemid species in the kidney of the small octopus Robsonella fontaniana collected in the southern Pacific Ocean on the central coast of Chile. Smeared renal tissues on glass slides and histological sections were prepared for microscopical observation. All host octopuses observed $(n=7)$ had dicyemids in the renal tissues. The dicyemids were Dicyemennea characterized by calottes composed of 4 propolar cells and 5 metapolar cells. This is the first record of dicyemids in Chile and also in R. fontaniana.
\end{abstract}

Key words: Cephalopod, dicyemids, mesozoa, Dicyemennea

\section{INTRODUCCIÓN}

Los diciémidos (Phylum: Dicyemida) son organismos invertebrados de pequeño tamaño que se alojan principalmente en los sacos renales de moluscos cefalópodos, usualmente han sido descritos como endosimbiontes o endoparásitos (Ogino et al. 2011). Los diciémidos presentan una organización corporal morfológicamente simple, compuesta por 8 a 40 células, sin cavidad corporal ni órganos diferenciados (Ridley 1968, Matsubara \& Dudley 1976a, 1976b, Furuya et al. 1996, Czaker 2000, Ogino et al. 2011, Catalano 2012). Los individuos vermiformes adultos tienen una región particular llamada calota, que le permite adherirse a las criptas o pliegues del túbulo renal de sus hospederos cefalópodos (Ridley 1968, Furuya et al. 1997, Furuya \& Tsuneki 2003). La calota presenta una organización definida, formada por dos grupos de células polares (propolares y metapolares), que se distribuyen de forma diferencial en ciertos grupos de diciémidos. De este modo, la calota ha sido considerada una estructura de gran importancia taxonómica dentro del grupo. Aproximadamente 112 especies de diciémidos han sido registrados mundialmente en 55 especies de cefalópodos bentónicos (Catalano 2012).

En América central, existe sólo un registro de diciémidos en la zona del Caribe (Penchaszadeh et al. 1996) y otros 2 registros en América del Sur, específicamente en Mar del Plata, costa Atlántica de Argentina (Penchaszadeh 1968, 1969, Penchaszadeh \& Christiansen 1970) y en las Islas Falkland (Malvinas) (Hochberg \& Short 1970). Existen otros hallazgos en la Península Antártica (Short \& Hochberg 1969, Short \& Powell 1969, Short 1971, Furuya $\&$ Hochberg 2002). Sin embargo, no existen antecedentes de este grupo de endosimbiontes para la costa del Pacífico Sur. El objetivo del presente estudio fue determinar la presencia y caracterizar los diciémidos en el pulpo pigmeo Robsonella fontaniana (d'Orbigny, 1834) obtenidos en la costa de Chile central.

\section{Materiales Y MÉTODOS}

Entre febrero de 2012 y julio 2013 se recolectaron 7 ejemplares de la especie Robsonella fontaniana en la zona del Muelle Barón, Bahía de Valparaíso, región central de Chile (3302’27,30”S 71³6’29,00’'O). La recolección de los pulpos fue realizada con trampas que consistían en tubos de PVC cerrados en un extremo con cemento. Las trampas fueron instaladas mediante buceo apnea y se mantuvieron sumergidas durante una semana. Los pulpos fueron extraídos y trasladados en un contenedor plástico de 20 L y llevados al laboratorio de la Facultad de Ciencias del Mar y de Recursos Naturales, Universidad 
de Valparaíso, para su posterior procesamiento. Los pulpos fueron mantenidos en acuarios por 20 días, alimentados con crustáceos decápodos y mantenidos a $13^{\circ} \mathrm{C}$ de temperatura. Los pulpos fueron pesados y disectados para extraer los riñones.

Para el análisis histológico, los riñones fueron cortados en 2 trozos de aproximadamente $5 \mathrm{~mm}^{2}$ y fijados en etanol al $70 \%$ por $2 \mathrm{~h}$, luego fueron preservados en solución de Bouin. El procedimiento de las preparaciones histológicas consistió en deshidratar el tejido en una batería creciente de etanoles $(70,80,90,100 \%)$ y finalmente en xilol absoluto. Luego, los tejidos fueron incluidos en parafina, para realizar cortes entre 7 y $10 \mu \mathrm{m}$ de espesor, utilizando un micrótomo MINOT. Posteriormente, los cortes fueron montados sobre portaobjetos de vidrio y secados en una estufa a $37^{\circ} \mathrm{C}$ por $24 \mathrm{~h}$. La tinción se realizó con Hematoxilina de Harris, y se contrastó con floxina alcohólica al 0,5\%. Finalmente, las muestras se sellaron con Entellán.

Complementariamente, otros trozos de riñón fueron usados para la preparación de esparcidos de diciémidos (i.e., frotis), es decir, en una gota de suero fisiológico, sobre un portaobjetos, se disectaron pequeñas secciones de tejidos, produciendo dispersión de los diciémidos. Los frotis fueron secados a temperatura ambiente, luego fijados en metanol absoluto y teñidos con Giemsa al $5 \%$. Los especímenes fueron observados en un microscopio compuesto LEICA DM LS2, hasta una magnificación del 1000X, y las imágenes fueron registradas mediante una cámara fotográfica digital LEICA ICC50 acoplada al microscopio.

Los caracteres morfológicos utilizados para la determinación taxonómica de diciémidos en este estudio fueron: el número y disposición de células polares (propolares y metapolares) en la calota, además de las características de los estados adultos (presencia/ausencia de nematógenos, rombógenos, embriones infusoriformes e infusorígenos (de células verruciformes con material granular refractario en su citoplasma) (Short 1991, Furuya et al. 2003, 2007).

\section{RESUltados Y Discusión}

\section{Presencia de diciémidos en el pulpo pigmeo}

Los 7 pulpos disectados eran machos y sus pesos oscilaron entre 51 y $119 \mathrm{~g}$. Además todos tenían diciémidos en el tejido renal. La calota de los diciémidos se encontró preferentemente adherida a los pliegues y/o criptas de

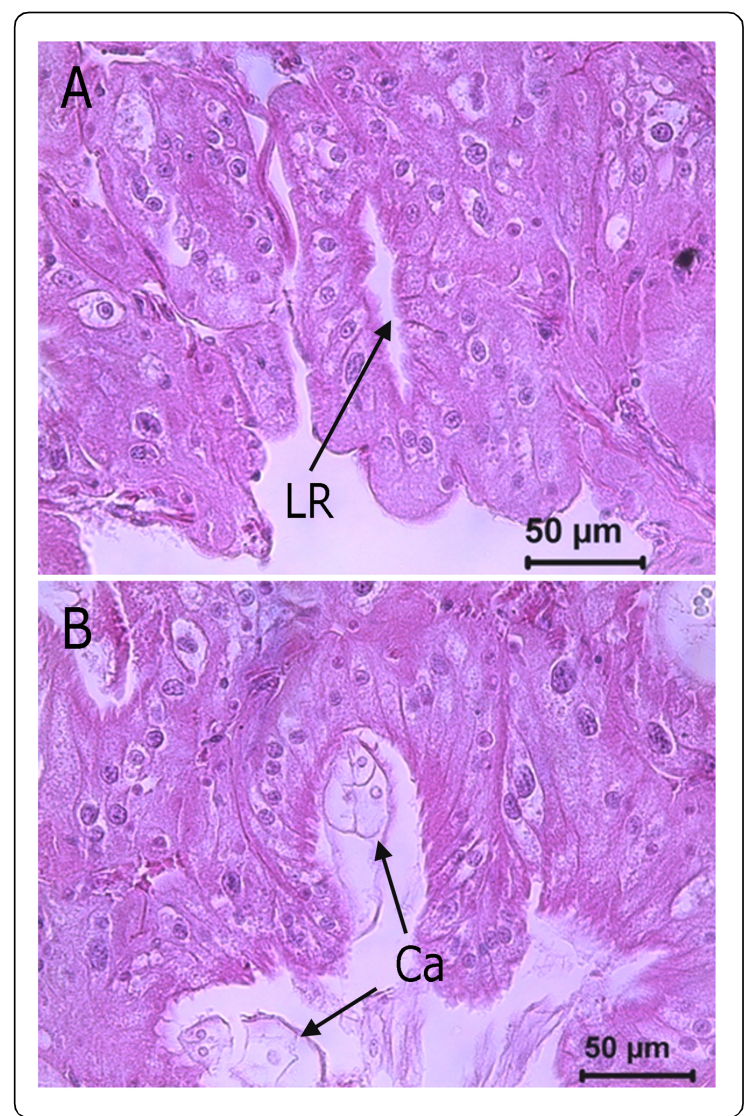

Figura 1. Secciones histológicas de túbulo renal de R. fontaniana: A) aspecto del epitelio sin diciémidos, B) calotas integradas al tejido renal, distinguiéndose parte del tronco de los rombógenos (LR: lumen del túbulo renal, Ca: Calota) / Histological sections of renal tubule of R. fontaniana: A) morphology of renal tubule without dyciemids, B) dicyemid calottes integrated the renal tissue, showing part of the rhombogen trunk (LR: renal lumen, Ca: Calotte)

los túbulos renales, lo cual desarmoniza el tejido renal normal (Fig. 1 A, B), sin embargo, la monocapa epitelial no muestra alteraciones celulares particulares, ya sea en su forma, polaridad (caras apicales y laterales), ni en su estructura interna.

Los especímenes observados en el presente estudio eran adultos rombógenos (Fig. 2A), que contenían embriones infusoriformes (Fig. 2B, C). No se encontraron adultos nematógenos. Los rombógenos presentaron cilios en sus células diapolares lo que los ubica en el orden Dicyemida (Short 1991). Además, la configuración de la calota corresponde al tipo I (forma cónica, Fig. 2D-F), que es una de las 3 formas que presentan los géneros del orden Dicyemida (Furuya et al. 2003). Esto confirma la 
presencia de diciémidos en el pulpo chileno Robsonella fontaniana.

Los diciémidos observados presentaron en la calota 5 células metapolares (Fig. 2E, F), con una disposición alternada en relación a las 4 células propolares que es concordante con el patrón que la literatura menciona para el género Dicyemennea Whitmann, 1883 (Short 1991, Catalano 2012).

\section{Caracterización general de los especímenes de DICYEMENNEA SP.}

Adultos vermiformes (15 ejemplares) cuerpo incluye la calota y el tronco. Longitud total entre 582 y $1133 \mu \mathrm{m}$. Calota de forma cónica. Etapas vermiformes con 4 células propolares, 5 células metapolares, 2 células parapolares y 2 células uropolares. Los ejemplares adultos vermiformes observados corresponden exclusivamente a rombógenos (Fig. 2a), con todas las estructuras reproductivas dentro

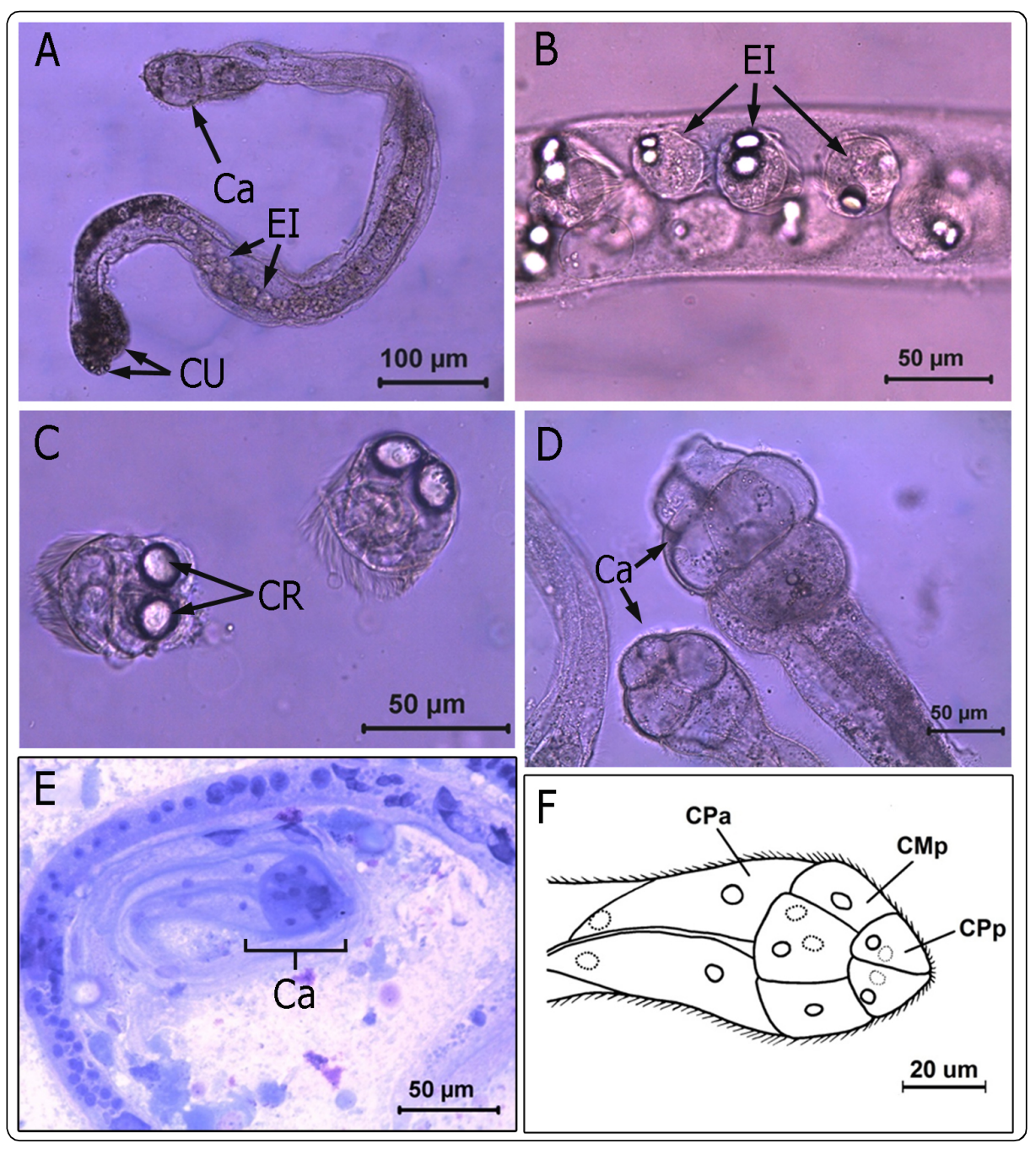

Figura 2. Diciémidos en estado de rombógenos, (A-D) transparencias in situ: A) cuerpo completo, B) un sector del cuerpo con embriones infusoriformes (EI) en estado de desarrollo avanzado, C) embriones infusoriformes libres, D) calotas completas, E) diciémido teñido con Giemsa, F) Representación de la distribución celular de la calota (Ca: Calota, CU: Células uropolares, CPr: Células propolares, CMp: Células metapolares, CPa: Células parapolares, CR: cuerpos refringentes) / Dicycemids in rhombogen stage, (A-D) without staining technique: A) complete rhombogen body; B) Part of the body containing infusoriform embryos (EI) in advanced stage of development, C) isolated infusoriform embryos, D) calottes, E) dicyemid stained with Giemsa, F) Display of the cellular distribution in a calotte (Ca: Calotte, CU: Uropolar Cells, CPr: Propolar cells, CMp: Metapolar cells, CPa: Parapolar cells, CR: refringent bodies) 
de la célula axial, es decir, con axoblastos e infusorígenos. También se observó la presencia de embriones infusoriformes con cuerpos sólidos refringentes (Fig. 2B). En relación al número de células diapolares, solamente se visualizaron en una monocapa celular indiferenciada rodeando el tronco (Fig. 2A, E).

Actualmente existen 40 especies de Dicyemmenea descritas a nivel mundial, ninguna de ellas en pulpos del género Robsonella, mientras que una especie de Dicyema, D. robsonellae Short 1971, fue descrita en Robsonella australis Benham, 1942 en Nueva Zelanda (Short 1971). Por lo tanto, este estudio constituye el primer registro de una especie de Dicyemennea en $R$. fontaniana en la costa del Pacífico Sudamericano. Futuros estudios podrían focalizarse en los estados reproductivos asexuales de este diciémido, no observados en el presente trabajo; su larva vermiforme y el adulto nematógeno, los que contribuirán con nuevos antecedentes para la descripción de la especie.

\section{Agradecimientos}

Esta investigación fue financiada por el Proyecto DIUV 16/2009 de la Dirección de Investigación de la Universidad de Valparaíso. Al Sr. Fidel Vargas, técnico del Departamento de Biología y Ciencias Ambientales, Facultad de Ciencias, por el procesamiento histológico de las muestras renales.

\section{LITERATURA CITADA}

Catalano SR. 2012. Areview of the families, genera and species of Dicyemida Van Beneden, 1876. Zootaxa 3479: 1-32.

Czaker R. 2000. Extra cellular matrix (ECM) components in a very primitive multicellular animal, the dicyemid mesozoans Kantharella antarctica. The Anatomical Record 259: 5259.

Furuya H \& FG Hochberg. 2002. New species of Dicyemennea (Phylum: Dicyemida) in deep-water Granelledone (Mollusca: Cephalopoda: Octopoda) from the Antarctic. The Journal of Parasitology 88: 330-336.

Furuya H \& K Tsuneki. 2003. Biology of dicyemid mesozoan. Zoological Science 20: 519-532.

Furuya H, K Tsuneki \& Y Koshida. 1996. The cell lineages of two types of embryo and a hermaphroditic gonad in dicyemid mesozoans. Development Growth \& Differentiation 38: 453-463.

Furuya H, K Tsuneki \& Y Koshida. 1997. Fine structure of a dicyemid mesozoan, Dicyema acuticephalum, with special reference to cell junctions. Journal of Morphology 231: 297-305.
Furuya H, FG Hochberg \& K Tsuneki. 2003. Calotte morphology in the Phylum Dicyemida: niche separation and convergence. Journal of Zoology 259: 61-373.

Furuya H, FG Hochberg \& K Tsuneki. 2007. Cell number and cellular composition in vermiform larvae of dicyemid mesozoans (Phylum Dicyemida). Journal of Zoology 272: 284-298.

Hochberg FG \& RB Short. 1970. Dicyemennea littlei $\mathrm{sp}$. n. and Dicyema benthoctopi sp. n.: Dicyemid mesozoa from Benthoctopus magellanicus. Transactions of the American Microscopical Society 89: 216-224.

Lapan EA \& HJ Morowitz. 1975. The dicyemid Mesozoa as an integrated system for morphogenetic studies. I. Description, isolation and maintenance. Journal of Experimental Zoology 193: 147-160.

Matsubara JA \& PL Dudley. 1976a. Fine structural studies of the dicyemid mesozoan, Dicyemmenea californica McConnaughey. I. Adult stages. The Journal of Parasitology 62: 377-389.

Matsubara JA \& PL Dudley. 1976b. Fine structural studies of the dicyemid mesozoan, Dicyemmenea californica McConnaughey. II. The young vermiform stage and the infusoriform larva. The Journal of Parasitology 62: 390409.

Ogino K, K Tsuneki \& H Furuya. 2011. Distinction of cell types in Dicyema japonicum (Phylum Dicyemida) by expression patterns of 16 genes. The Journal of Parasitology 97: 596-601.

Penchaszadeh PE. 1968. Diciémidos (Mesozoa) en cefalópodos de Argentina Dicyema australis sp. nov. parásito del pulpo Octopus tehuelchus d'Orb. Neotropica 14: $127-131$.

Penchaszadeh PE. 1969. Una nueva especie de Dicyemidae (Mesozoa) parásito del pulpo Octopus tehuelchus d'Orb. and Dicyema platycephalum. Neotropica 15:1-6.

Penchaszadeh PE \& HE Christiansen. 1970. Conocyema marplatensis sp. nov. (Mesozoa, Dicyemidae) parásito del pulpo Octopus tehuelchus d'Orbigny. Neotropica 16: 119123.

Penchaszadeh PE, JM Gómez, C Izsak \& R Rodríguez. 1996. First discovery of Dicyemida (Mesozoa) in Caribbean cephalopods. Journal of Molluscan Studies 62(3): 397-398.

Ridley RK. 1968. Electron microscopic studies on dicyemid Mesozoa. I. Vermiform stages. The Journal of Parasitology 54: 975-998.

Short RB. 1971. Three new species of Dicyema (Mesozoa: Dicyemidae) from New Zealand. In GA Llano \& IE Wallen (eds). Biology of the Antarctic Seas IV, Antarctic Research Series 17: 231-249, American Geophysical Union, Washington. 
Short RB. 1991. Marine flora and fauna of the Eastern United States: Dicyemida. NOAA Technical Report NMFS 100: 1-16.

Short RB \& FG Hochberg. 1969. Two new species of Dicyemennea (Mesozoa: Dicyemidae) from Kaikoura, New Zealand. The Journal of Parasitology 55: 583-596.
Short RB \& EC Powell. 1969. Dicyemennea eltanini sp. n. (Mesozoa: Dicyemidae) from Antarctic waters. The Journal of Parasitology 55: 794-799.

Recibido el 17 de enero de 2013 y aceptado el 2 de septiembre de 2013

Editor: Claudia Bustos D. 